\title{
Uma experiência com educação intercultural indígena: entreuista com a professora Joziléia Daniza Kaingang
}

\author{
Elison Antonio Paim ${ }^{1}$ \\ Universidade Federal de Santa Catarina, Docente no Departamento de Metodologia de \\ Ensino do Centro de Educação \\ Pedro Mülbersted Pereira ${ }^{2}$ \\ Universidade Federal de Santa Catarina, Membro do Grupo Patrimônio, Memória e Educação
}

Resumo: A Licenciatura Intercultural Indigena do Sul da Mata Atlântica da Universidade Federal de Santa Catarina (UFSC) tem a proposta de atender os povos indígenas que vivem na parte meridional da Mata Atlântica: Guarani (ES, RJ, SP, PR, SC, RS), Kaingang (SP, PR, SC, RS) e Xokleng (SC), com Ensino Médio completo ou em conclusão, desde 2010. 0 curso está estruturado em regime presencial especial, com etapas concentradas divididas entre Tempo-Universidade e Tempo-Comunidade, de acordo com a perspectiva da Pedagogia da Alternância. Joziléia Daniza Jagso Inácio Schild é, atualmente, a Coordenadora Pedagógica desse curso. Joziléia Daniza Jagso Inácio Schild nasceu na Terra Indígena do Guarita, território indígena Kaingang localizado no Município de Tenente Portela, RS. É graduada em Geografia pela Universidade Comunitária da Região de Chapecó (Unochapecó) (2010), especialista em Educação de Jovens e Adultos Profissionalizantes pela Universidade Federal do Rio Grande do Sul (UFRGS) (2012), mestre em Antropologia Social pela Universidade Federal de Santa Catarina (2016) e está, atualmente, cursando Doutorado em Antropologia Social pela Universidade Federal de Santa Catarina (UFSC). Entrevistamos a professora Joziléia Kaingang em março de 2018. Na ocasião, a entrevistada compartilhou suas experiências com a Licenciatura Intercultural Indígena como estudante, como educadora e com as atuais lutas e pautas dos povos indigenas no Brasil.

Palavras-chave: Educação escolar indígena. Educação diferenciada. Licenciatura intercultural indígena.

Recebido em 25 de abril de 2018

Aceito em 28 de setembro de 2018

Publicado em 19 de fevereiro de 2019

Elison Paim (EP): Hoje, dia 7 de março de 2018, estamos na Coordenação da Licenciatura Intercultural Indígena da Universidade Federal de Santa Catarina para uma entrevista com a

Doutor em Educação pela Universidade Estadual de Campinas; Mestre em História pela Pontificia Universidade Católica de São Paulo; https://orcid.org/0000-0002-7509-5572; http://lattes.cnpq.br/8695520812750828.

2 Mestre em Educação pela Universidade Federal de Santa Catarina; Graduado em História pela Universidade Federal de Santa Catarina; https://orcid.org/0000-0002-2045-294X; http://lattes.cnpq.br/7404888329203446. 
professora Joziléia, que nos falará um pouco da experiência da educação intercultural indígena, além da sua trajetória e das reivindicações dos povos indígenas quanto à educação, as quais poderão ser verificadas na obra coletiva organizada por professores vinculados à licenciatura intercultural da Universidade Federal de Santa Catarina (UFSC) (NÖTZOLD; ROSA; BRINGMANN, 2012). Joziléia, apresente-se, por favor. E fale sobre você, sobre a tua trajetória.

Joziléia Daniza Kaingang (JDK): Sou Joziléia Daniza Kaingang - a gente coloca o Kaingang no final porque não é meu sobrenome, mas é o nome do meu povo, é a maneira que a gente tem se colocado para que as pessoas saibam de que lugar a gente vem, de que povo a gente está falando. Eu saí do Rio Grande do Sul. Nasci na Terra Indígena do Guarita, que é do Município de Tenente Portela. Minha família foi morar em Ronda Alta, em uma retomada de uma terra indígena - que é a Terra Indígena na Serrinha, lugar onde meu avô viveu, enfim, houve a expulsão daquele território e, na década de 1990, a retomada do território. Eu estudei lá, em escola pública de Ronda Alta, e fui fazer a minha graduação na Unochapecó, no Curso de Geografia, licenciatura plena. Foram quatro anos do Curso da Graduação.

Logo depois do curso de graduação, fui fazer especialização em PROEJA Indígena, uma proposta diferenciada para indígenas, pela Universidade Federal do Rio Grande do Sul. Foram dois anos lá; e depois fui trabalhar em Brasília - porque eu já trabalhava com instituições não governamentais, com institutos, o Instituto Kaingang e o Instituto Indígena Brasileiro para Propriedade Intelectual. Trabalhei com eles em Brasilia por um tempo, e já tinha a pretensão de continuar estudando para atuar na educação, porque minha família vem de muitos professores indígenas - minha tia e minha mãe são monitoras bilíngues.

Resolvi fazer pós-graduação e comecei a pedir para as universidades federais acesso diferenciado a indígenas. Escrevi para várias universidades - inclusive para a UFSC; escrevi cartas para a reitoria, para os coordenadores de Programa da Antropologia Social que era o que eu gostaria de cursar - pedindo essas vagas. Obtive resposta positiva aqui da Federal de Santa Catarina e da Federal de Pelotas, e então lançaram no edital daquele ano (2013) essa vaga de acesso para indígenas e negros. Ingressei aqui na UFSC; fiz o mestrado. Quando encerrei o mestrado, em fevereiro de 2016, recebi o convite para trabalhar aqui na Coordenação Pedagógica da Licenciatura Indígena.

Em 2016, iniciei junto com a turma que iniciou - uma nova turma de 45 alunos: 15 guarani, 15 kaingang, 15 laklaño/xokleng, todos falantes da língua, porque um dos critérios do vestibular para o ingresso dos indígenas era a prova (redação) na língua do seu povo. A maioria dos nossos alunos são professores que já estão em sala de aula. Acho que têm umas duas pessoas só que não são. A maioria já tem experiência como docentes, alguns 
deles com mais de 15 anos de sala de aula; a maioria deles fizeram o Magistério Indígena, seja a formação que houve no Rio Grande do Sul ou em Santa Catarina.

Para mim, foi uma experiência extremamente interessante, porque sempre imaginei trabalhar com formação (sempre desejei ser professora formadora, de curso superior), mas nunca tinha imaginado que trabalharia com um curso de Licenciatura Intercultural, que tem uma outra abordagem, que é, realmente, a valorização da cultura, valorização da língua. 0s docentes que trabalham com a Licenciatura Indígena, embora trabalhem as suas disciplinas, levando em consideração o padrão de excelência, também se preocupam em entender o contexto do qual vêm os seus alunos e, também, qual é a demanda de formação destes, porque isso implicará na escola, quando estes então professores trabalharem com os seus estudantes indígenas nas suas escolas indígenas. É a busca por ter uma escola indígena com ensino diferenciado e de qualidade.

EP: Explique-nos o que é essa educação diferenciada e porque os indígenas têm de ter uma educação diferenciada.

JDK: 0 processo de educação com os povos indígenas foi um processo de valorização da cultura do não indígena, de imposição cultural. Um dos lugares em que tivemos, talvez, os maiores danos às nossas populações foi através da educação, da inserção da escola e dessa obrigação que os povos indígenas tinham de aprender o português, valorizar a cultura do não indígena, valorizar o que vinha de fora em detrimento da sua [cultura]. Sempre o do outro era superior.

A minha tia Andila (que também é minha mãe) sempre fez essa discussão, há muitos anos, e falava para a gente que a educação e a escola vieram como uma forma de opressão e de descaracterização da cultura indígena.

A educação diferenciada é uma educação que leve em conta tudo o que devemos ter de bom e de qualidade em uma educação para formação de uma pessoa, mas que leve em consideração, principalmente, a cultura desse sujeito, a cultura dos povos indígenas, e cada um conforme as suas especificidades, que essa é, também, uma grande discussão: que considere a língua, a cultura, a tradição desses povos; que considere um calendário diferenciado - porque as nossas tradições são distintas das tradições do não indígena, porque fazemos o feriado de Nossa Senhora Aparecida e não há um recesso quando se faz a busca da visão do povo guarani, por exemplo. Fazemos o feriado da Independência do Brasil e não fazemos um recesso escolar quando temos, por exemplo, uma Festa do Mastro, que acontece na Terra Indígena do Inhacorá, que é uma festa tradicional, com Kujás e tudo mais; ou mesmo o encontro dos cunhãs 
Kujás em Porto Alegre, um evento grande entre os Kaingang, e não é um recesso escolar! Mas cumprimos os outros recessos que nos são impostos.

Essa educação diferenciada é uma necessidade de que se valorizem as nossas tradições! E todo povo tem uma [tradição] [...] isso é interessante, também. Porque as pessoas colocam os povos indígenas em um balaio de gato: é todo mundo misturado, todo mundo é igual. E não, nós não somos todos iguais, nós somos muito diferentes! Embora nós tenhamos, hoje, uma luta muito igual, que é a luta dos povos indígenas por uma educação de qualidade, diferenciada; por território; enfim, por saúde, que são as várias lutas que nós temos.

EP: Fale um pouco dessas lutas, nos dê alguns exemplos de lutas que vocês vem desenvolvendo (que é uma longa trajetória dessas lutas todas).

JDK: 0 que está em pauta, e que se discute muito, hoje - embora já tenha se discutido lá na década de 1970, 1980, na constituição da Constituição Federal (risos), quando se pensou, então, alguns artigos que falavam dos povos indígenas... acho que o grande nome de pauta de luta é terra. Os povos indígenas foram expropriados do seu território; foram violentamente colocados em territórios diminutos, que nem eram os seus de tradição, e tiveram que conviver com clãs opostos - o que ocasionou vários tipos de violência dos não indígenas para com os indígenas, mas, também, entre os próprios indígenas. A grande pauta de luta do movimento indígena, hoje, é o direito à terra.

0 que nós vemos é que faz alguns anos já que nós não temos demarcação de territórios. Nós tivemos a grande conquista, que foi Raposa Serra do Sol, no Norte do País; mas não vemos uma demarcação de território para povos que são grandes e que têm terras pequenas - que é o caso do povo Kaingang. Por exemplo: há vários acampamentos no RS, principalmente na região de Passo Fundo, e o que vemos é que ali era um grande território de circulação Kaingang! E, hoje, eles estão em pequenos territórios e uma grande população, o que ocasiona vários conflitos internos; muitas famílias ficam à beira da estrada, reivindicando outros territórios, que eram territórios tradicionais, porque, realmente, não dá para viver em um pequeno território com muitas famílias! E o governo não tem feito ações reais para que se efetivem essas reocupações desses territórios tradicionais.

A outra grande pauta dos povos indígenas... bom, tem várias pautas, mas as maiores, hoje, são Saúde e Educação.

Na Saúde, nós tivemos uma mudança muito interessante, que foi a mudança da Funasa, que cuidava da saúde indígena, para a Sesai - que é a criação da Secretaria da Saúde Indígena, dentro do Ministério da Saúde, fazendo uso do sistema SUS. Tem ganhos e tem 
perdas: nós ficamos pensando o que é melhor, se é melhor agora, Sesai, ou se era melhor a Funasa. E não sou da área da Saúde, mas vejo que tivemos alguns avanços no início, sim, como a contratação de profissionais indígenas, principalmente o pessoal que estava se formando na área da Enfermagem; nós temos alguns médicos indígenas que estão trabalhando nesse contexto de Sesai. Mas nós temos várias perdas, por exemplo: desvio de recurso da área da Saúde. Isso é bem complexo. Não tenho muito aprofundamento para explanar melhor.

E na Educação? Eu acho que na Educação, que é a minha área, tivemos inúmeros avanços, mas tivemos alguns retrocessos também. A Educação teve, por exemplo, nos estados aqui do Sul, no Rio Grande do Sul, a contratação de vários professores indígenas através de concurso público, em 2012, 2013; isso foi bem importante: dois concursos públicos com o ingresso de professores indígenas, o que é muito importante, e que, infelizmente, eles não estão nas direções das escolas! Se você tem uma escola indígena, dentro de uma terra indígena, com professor concursado, por que a maioria dos cargos ocupados por coordenação pedagógica não é indígena? Por que a maioria dos cargos ocupados por diretores de escola não são por indígenas? E o que me vem muito na conversa com outros indígenas é que, bem, então ainda se coloca o não indígena como o que tem que comandar, o que sabe gerenciar; o gestor melhor vai ser o não indígena.

Questiono os colegas que são professores indígenas nas terras indígenas como eles aceitam que um coordenador pedagógico possa ensinar-lhes como fazer melhor o uso do tempo que eles têm para trabalhar a tradição indígena, por exemplo? Para trabalhar cultura indígena, artesanato, língua... como é que esse coordenador pedagógico, que é não indígena, pode ter essa sensibilidade maior do que um indígena para estar nessa coordenação pedagógica nas escolas? São questionamentos! Não sei a resposta! Mas imagino que se as coordenações pedagógicas fossem com professores indígenas, talvez, eles soubessem levar até a Secretaria de Educação essa necessidade de fazer outros tipos de feriado, por exemplo, que foi o que falei no início. É um pequeno exemplo.

Sem falar de tudo o que pode ser trabalhado na Matemática, na Ciência, usando como fio norteador um conhecimento indígena. Nós temos tempos de contar, que é o tempo da taquara; nós temos o tempo de gestar, que é o tempo em que a planta é pequena, e que as mães engravidam e têm o parto; tudo isso poderia ser trabalhado dentro de um contexto de sala de aula com um fio norteador para um período de escola. E, infelizmente, não é. Por quêe Os valores que estão em um patamar maior ainda são os da cultura não indígena! lsso é bem importante, e preocupante.

E nós tivemos avanços nas universidades! Hoje, nós temos o que é uma luta, desde quando entrei na universidade, que as universidades que primeiro nos acolheram, na região Sul do Brasil, foram as universidades privadas! Foram as universidades comunitárias! lsso é muito importante. Nós somos uma leva de formados por esta universidade que gerou esse desejo 
de outras pessoas ingressarem na universidade, mas viemos de universidades particulares e universidades comunitárias, que foram essas que abriram as portas para nós. As primeiras que abriram (Unijuí, UPF, Unochapecó, Unoesc, tantas outras); mas lembro o que é da minha região, do meu contato, e que formaram vários dos meus primos e das minhas primas, vários outros parentes que eu conheço, que vieram desses lugares. São essas pessoas que lutaram por vagas em universidades públicas, pelo sistema de cotas - seja por vagas suplementares, como nós temos aqui na UFSC, e tantas outras Federais e Estaduais que abriram esse sistema de vagas suplementares, que é superinteressante porque aquele discurso que as pessoas têm de "O indígena e o quilombola estão tirando a vaga do meu filho! Está tirando vagas dos não indígenas!" cai por terra! Porque a vaga suplementar é criada além! Então se destinam aquelas vagas: se são cem vagas, são cem vagas; tem quatro alunos indígenas, tem quatro quilombolas? Então, são 108 (cento e oito) vagas, porque são complementares. Isso é muito importante. E as vagas nas pós-graduações - o que, aqui na UFSC, vejo com muitos bons olhos, embora penso que está caminhando a passos de tartaruga! Nós temos aí a Federal de Pelotas (UPPell que, no ano passado, instituiu para todos os cursos de pós-graduação reserva de vagas para indígenas e negros. Isso é um avanço substanciall A UFSC começou com a Antropologia; em 2013, lançou o edital; em 2014, ingressei; nós temos aí o ingresso de negros e indígenas - um para mestrado, negro; um para mestrado, indigena; um para doutorado, negro; um para doutorado, indígena. $\mathrm{E}$ agora a História abriu nesse ano (2018), no ano passado (2017) foi o edital, acredito, ingresso nesse ano, nós temos também reserva de vagas para indígenas e negros - o que é uma vitória! Acredito que a UFSC precisa abrir para os demais programas, a Educação principalmente, porque nós temos vários professores formados em Educação e que gostariam de continuar com mestrado e doutorado. Ter esse acesso - visto que nós temos um número de indígenas e um número de comunidades e terras próximas aqui à Federal de Santa Catarina (UFSC) bem importante, um quantitativo interessante, penso que é primordial fazer essas discussões dentro dos colegiados e aprovar vagas! Vejo que foram avanços superimportantes na área da Educação.

EP: Joziléia, fale-nos como é que se dá a relação, por exemplo, entre os conhecimentos próprios de cada povo - Kaingang, no teu caso, e os demais - e esse conhecimento da escola. Como vocês vem lidando com isso? Como se dá essa relação, hoje, entre os conhecimentos tradicionais e os conhecimentos escolares? Como vocês tem conseguido inserir os conhecimentos de vocês dentro da escola?

JDK: Me lembro, desde muito cedo... os Kaingang têm uma facilidade muito grande com a oralidade. Nós somos povos orais. Quando eu era criança ouvia os relatos, os contos da minha mãe, das minhas tias - que são, por nós, por mynh si (mãe pequeninha), que são nossas mães também -, ouvia os relatos delas de como acontecia o ingresso na escola. A violência a que eram 
submetidos! A Funai - na época SPI - obrigava os pais a mandarem os filhos para as escolas, e quem lecionava nessas escolas, normalmente, era a esposa do chefe de posto. Eles aplicavam castigos severos às crianças indígenas quando elas falavam na língua; não podia falar na língua! Tinha uma série de coisas que eram obrigadas a fazer, como limpar a escola; às vezes, limpar o quintal da casa do chefe do posto. E eram crianças de sete, oito anos, e que apanhavam de todos os professores. Essa violência, hoje, não existe mais. lsso é muito interessante.

Como foi se construindo, então, com essa cara mais indígena? A partir do momento que os primeiros monitores bilíngues foram formados - eles não eram chamados de professores, eram chamados de monitores bilíngues -, eles foram vindo para a escola para fazer a alfabetização nas línguas. Isso no contexto dos Kaingang. Alfabetizando nas línguas, eles facilitariam a alfabetização na língua portuguesa, e isso era uma violência! $E$ isso também ia levar a ter um produto, no final, que é um pouco do que a gente vê de pessoas que não se encontravam, não sabiam o que é melhor: se é melhor você ser indígena, se é melhor não ser indígena. Isso gerou muito conflito em algumas gerações.

A escola foi ganhando, com os monitores bilíngues - embora tenha sido um enfrentamento muito difícil, porque, na época, as escolas eram escolas federais, então, as ordens vinham muito de cima para baixo. Eles não tinham direito a nada. Por exemplo: mandavam, para a escola indígena, latas de leite em pó. Nós não tomávamos leite, nem em pó! Então o leite em pó estragava. Almôndega! Os Kaingang não comem carne de gado, assim, seguidamente! Temos uma preferência por carne de porco, de frango, mas principalmente de porco. Me lembro disso quando era criança, de ver as latas de almôndega. $E$ isso foi mudando. Hoje, na escola indígena as merendeiras podem fazer comida tradicional. Época de caraguatá, por exemplo, que é uma comida, elas fazem; época de fuá, elas fazem com as crianças. Envolve. Tem algumas coisas que foram se modificando, e para o bem. Assim como ter professor indígena em sala de aula é uma forma de valorizar o ser Kaingang, o ser indígena, porque você mostra para a criança, principalmente para o adolescente, que está em uma fase de não entender muito os conflitos que tem a adolescência - porque não tínhamos isso, passávamos de criança para adulto; agora existe essa fase de adolescente. E também nós, comunidade, indígenas, temos que aprender a lidar com essa fase que veio com a cultura do não indígena, do mundo, enfim. Hoje falamos de adolescência também. E é mostrar para eles que, bom, você pode ser indígena e você pode ser professor, enfermeiro, médico... pode ser astronauta, se quiser, sem deixar de ser indígena! E é esse valorizar, mesmo, o professor indígena que está lá dentro.

Acredito que a escola teve muitas mudanças. Hoje você chega em terras indígenas que a escola está toda pintada de grafismo, e as crianças sabem o significado daqueles desenhos que elas fizeram nas paredes. Há um tempo atrás, se você perguntasse para um jovem, talvez ele não dissesse - ou porque ele não queria dizer, porque tinha vergonha, ou porque realmente não sabia qual era a marca dele (entre os Kaingang nós temos duas 
metades; ele não saberia se ele era Kamé ou Kanhru kre, não saberia se a metade dele é ioruté rá tej ou ororô rá ror). Essas coisas são bem importantes nesse contexto de criação da nova escola, desse olhar para a nova escola indígena.

EP: Joziléia, você vem da Geografia, inclusive foi minha aluna (risos), mas na Geografia, e pensando que nós - eu e o Pedro - viemos da História, diga-nos como é que se dá a relação da História escolar, do livro, e a História de vocês? Como vocês trabalham com isso? Com o espaço, também. Como trabalham com isso?

JDK: Em um contexto mais de escola mesmo - e aí vou falar primeiro disso, para, depois, falar da licenciatura indígena - vejo que a escola indígena ainda está muito nos moldes da escola não indígena, em uma escola pensada pelas Secretarias de Educação, que manda os livros para a escola, que fala o que o professor tem que trabalhar, o conteúdo programático do ano, da série, e o professor tem que aplicar aquilo, e a escola segue os caminhos que a Secretaria de Educação vai trazendo - muitas vezes, impondo. Algumas vezes, sim; outras vezes, não; mas, muitas vezes, na maioria das vezes, impondo.

Como curso formador, nós temos trabalhado com os alunos que serão os professores lá nas escolas um pensamento de que eles têm que trabalhar, sim, com o conhecimento que foi produzido, que está no livro, que tiramos aqui dessa Ciência que eles vieram buscar na Academia; mas que eles têm que valorizar o modo de fazer, o modo de ensinar... essa pedagogia indígena que eles têm que aplicar, também, com esse conhecimento! Valorizar o falar, a oralidade. Valorizar a escrita, sim! Mas valorizar a oralidade. E isso tem acontecido nas diversas disciplinas que nós temos. Nós vemos os professores trabalhando textos, dando as aulas, eles têm que escrever, mas eles têm um momento, também, da oralidade, e de valorizar essa fala. Porque você não pode avaliar um povo que vem de uma tradição oral só pela escrita. Ou só pela apresentação da leitura que ele fez. A leitura que ele fez pode ser uma representação; mas, talvez, o entendimento que ele tenha tido sobre aquilo que leu nem sempre vai conversar com o entendimento que o professor não indígena faz daquele texto. Isso é bem interessante!

Vejo que o que tem acontecido com os professores formados nessas licenciaturas interculturais é que eles têm buscado fazer - muitas vezes contrários à orientação da Secretaria de Educação - uma escola diferente! Por exemplo: eu visitei a Terra Indígena Xapecó, e eles estavam se organizando para a festa do Dia do Índio. 0 que eles fizeram? Os alunos pintados; eles tiveram várias aulas sobre a cultura indígena, sobre a tradição - não posso falar, talvez, de cultura, mas de tradição que temos hoje... porque não vamos voltar, também, há 500 anos; nós não seremos mais os mesmos Kaingang de 50 anos atrás! lsso é bem importante. Sou 
estudante, sou professora... bom, não sou, talvez, a mesma indígena Kaingang que há 50 anos seria. As pessoas também precisam ver isso porque é uma crítica que nós recebemos.

Na escola do Xapecozinho eu os vi se preparando da maneira como eles tiveram entendimento da tradição. E nem sempre é aquilo que está contado no livro que um missionário escreveu, que um antropólogo escreveu, que um historiador escreveu. É como eles estão vendo a tradição, atualizada! Acredito que a escola tem feito um papel bem importante, porque as escolas indígenas, hoje, têm, talvez, um papel central em guarda de memória. Porque ali na escola acontecem as coisas, as reuniões de liderança, muitas vezes; acontecem as apresentações culturais. Fico pensando no significado que tem esse espaço dentro das terras indígenas, como um local de memória do que era passado, do que é o presente e do que tem que se atualizado nessas tradições. Considero a escola dentro das terras indígenas, talvez, um espaço fundamental, hoje. Pelo menos entre os Kaingang. Mas penso que também para muitos outros povos.

EP: A partir dessa retomada, dessa ressignificação por vocês mesmos...

JDK: Isso, isso! Dessa ressignificação. Não a partir da escola que nos foi apresentada, que nos foi imposta, mas dessa ressignificação do espaço da escola! 0 que é bem interessante, porque acredito que isso deve acontecer em vários povos, mas entre os Kaingang é essa tomada do que é de fora e dessa apropriação que ele faz sobre aquilo! 0 que é uma discussão bem ampla. Por exemplo: dos não indígena que moraram há algum tempo dentro das terras indígenas e dessa apropriação que eles fizeram dessa pessoa, desse sujeito (risos)... no trato, no olhar ele com um olhar mais assimétrico e não com essa diferença. Isso é bem interessante entre os Kaingang. Entre as estruturas, também: essa apropriação do posto de saúde, da escola, que passa a ter esse novo sentido.

EP: 0 que é muito forte, a presença do não indígena, e no olhar para vocês, dizer: “Bom, você, Joziléia, professora da universidade, é doutoranda, não é mais indígena." Como vocês lidam com isso?

JDK: Isso é bem complexo para nós! Em um primeiro momento, vivi isso muito na minha graduação, porque vim de uma turma que... a minha turma não era uma turma racista, de forma alguma; nunca sofri racismo na minha turma. Mas vim de uma turma que só tinha eu que era indígena; tinha uma turma que estava adiantada, na minha frente, que tinha um indígena, o Fernando. As pessoas falavam assim: “Joziléia, mas você veio estudar aqui na cidade; você fala português direito; você está aqui conosco; você faz os trabalhos... você não 
parece mais indígena! Você não é mais indígena!" Quer dizer: o que acontece? Realmente! Não sou uma Kaingang que faz artesanato, por exemplo. Eu faço o meu artesanato, gosto, quando tenho tempo; gosto de pintar; eu fiz estas telas laponta para as telas que estão expostas na sala da Coordenação]; dá um outro significado ao artesanato, ao que ele tem de referência para a minha vida. Mas não sou artesã. Sou professora. E ser professora é você ter algumas características que vão te diferenciar! Assim como você ser cunhã vai ter características que não vá te diferenciar; assim como ser enfermeiro.

0 que é diferente é que quando estamos do lado de cá, as pessoas acham que porque você adquiriu um conhecimento, ou porque você está tendo uma postura de falar sobre os mesmos direitos, principalmente, você deixou de ser indígena. Faço essa relação: se você morar no Japão, nascer no Japão, e você for morar na China, embora você se pareça muito - e para nós, que estamos aqui no lado do 0cidente, quando vemos um japonês, um chinês, um coreano, pensamos que é tudo a mesma coisa - também, para o não indígena a gente parece isso. Mas não é! 0 chinês não vai deixar de ser chinês; o japonês não vai deixar de ser japonês, e o coreano não vai deixar de ser coreano! Assim como nós, indígenas.

Embora você tenha toda essa outra apresentação e essa sedução - porque este mundo aqui é uma sedução. Você é seduzido a querer comer pizza e a não querer comer Peho Fel! Agora, eu tenho que saber o significado, para mim, de comer Peho Fej e o que é comer pizza. Você saber que você não vai deixar de ser indígena porque você comeu pizzal Embora você possa preferir comer pizza! São essas discussões que acredito que devem ser melhor aprofundadas, entre nós, indígenas, mas, também, com o não indígena. Porque o não indígena costuma nos rotular. "Ah, não, você está com um tom de pele mais claro, então você não é indígena"; "Você está usando uma aliançal Então você não é indígena”; "Você tem um celular? Então você não é indígena”; "Você tem um carro? Você não é indígena"; "Você tem uma casa na cidade? Você não é indígena." Muitas vezes não é isso o que acontece. Você tem uma casa na cidade porque, bom, você passou a morar na cidade, está trabalhando aqui... com a causa indígena, você precisa morar em algum lugar! Não vai morar embaixo da ponte ou na aldeia! Não tem como! Então, são coisas que vão acontecendo, mas que não vão te descaracterizar de pertencer a uma comunidade. Você saber o seu pertencimento, a tua história de vida, história dos teus pais, dos teus avós, dos teus irmãos. As pessoas me falam, assim: "Os teus irmãos moram na aldeia! Por que você não mora na aldeia?" Bom, porque eu trabalho aqui na Licenciatura Indígena em Florianópolis. É impossível morar na aldeia! Só que isso, às vezes, não é considerado.

Eu acho isso tão interessante porque o não indígena pode morar onde ele quiser. Bom, nós também podemos morar onde quisermos. Podemos viver como quisermos. Só que isso gera um grande conflito. Aí, já não sei se é um conflito que temos de ter entre nós, porque passamos por um momento de conflito, sim, ou se temos que deixar os outros pensarem o que quiserem pensar e seguirmos o nosso caminho. Penso que esse é o caminho 
mais fácil. Agora, quando vemos chamado sobre isso, sempre gera muita polêmica. E aí vão ter os indígenas que vão responder de uma maneira mais educada e calma, como vão ter aqueles que vão dizer: "Escuta, mas o que você tem a ver com isso? Eu posso morar onde quiser, comer o que quiser e falar o que quiser." Acredito que isso vem se atualizando.

Mas, também, tem uma outra coisa que é bem importante: o que você quer ver do indígena? Quando fui fazer Antropologia era uma das coisas que sempre me questionava. Porque as Kaingang, assim, é difícil você não ver uma Kaingang que não goste de usar uma roupa colorida, vermelho; que não goste de um batom vermelho. Nós gostamos de cor! Gostamos de cor vibrante: amarelo, vermelho, verde, liás... pode ver pelo nosso balaio! Nossos balaios são todos coloridos, bem significativos. E quando vim fazer Antropologia, via todo mundo vestido igual - talvez eu até esteja muito parecida com isso: vestindo calça marrom, roupa preta, ou, roupa branca, nada muito colorido! E me sentia muito mal, porque as minhas roupas eram coloridas. E ficava pensando... até que, no final do segundo semestre, conversei com uma outra indígena, que é peruana, que me falou: "Jozi, você tem que se vestir do jeito que você gosta! Eles é que são não indígena antropólogos! Você vai ser uma antropóloga indígena! Você vai ser diferente! Então tudo bem de você não vestir a mesma cor de roupa que os outros." Mas nós também entramos nesse conflito. Porque, às vezes, nós ficamos, também, o que o outro quer ver de nós.

E essa é uma grande discussão sobre usar artesanato, plumária, sobre sair por aí pela universidade pintado. De vez em quando eu me pinto. Mas a pintura, para mim, tem de ser em um momento muito especia! Um momento de uma representação simbólica muito importante. Porque não preciso usar ela [pintura] no meu cotidiano para ser indígena. E é uma discussão que o Daniel Munduruku faz muito bem. Ele fala: "Eu não preciso estar de cocar todo dia para você saber que eu sou índio."

EP: Tentando fechar: poderia deixar algum recado ou alguma coisa que queira frisar em relação à Educação Indígena? Essas questões todas que você foi explanando para nós? Fique à vontade. Se quiser dar algum recado... Que vá para o mundo!

JDK: Bom, penso que é muito importante valorizar o profissional indígena da Educação, com a sua sabedoria, com o seu conhecimento, que é diferente - porque nós não viemos sem saber nada. Quando nós viemos para a universidade trazemos toda uma bagagem de conhecimento, de tradição, de conhecimento também de educação, de formas de educação. E acredito que a universidade, os programas, precisam considerar esse conhecimento que nós trazemos, que nos é próprio, essa pedagogia própria. Isso é fundamental! E que as escolas indígenas tenham, realmente, essa cara indígena! Que o Estado pare de interferir tanto do jeito que eles inferem! Que valorizem os profissionais indígenas que 
são formados - muitos aqui na Universidade Federal [de Santa Catarina], muitos em outras universidades, que valorizem esse profissional! Que ele possa ser diretor de escola, que ele possa ser coordenador pedagógico, porque ele tem potencial! Acredito que valorizar os profissionais vai dar uma cara nova e, realmente, uma educação diferenciada para os povos indígenas. Não nos basta ter disciplina de língua indígena. Precisamos que todas as disciplinas falem da nossa tradição, da nossa cultura, da nossa língua, dos nossos valores, enfim. Isso sim formaria escolas indígenas, e não as escolas que temos, que o Estado traz sempre com a sua supervisão, sempre com o seu entendimento sobre o que é escola.

Penso que o valor de Ciência tem de ser igualitário. Não é a nossa Ciência que vale mais, e não é a Ciência do não indígena que vale mais: acredito que os valores da Ciência têm de ser iguais! Quando as pessoas nos falam assim: "Mas de que Ciência você fala?", posso dizer que, bom, aprimorar uma semente de milho para que ela fosse comida quando os colonizadores chegaram, isso foi uma Ciência! Uma Ciência primorosa que, talvez, uma tecnologia, hoje, levasse anos para conseguir aprimorar. Uma mandioca, que é tão saboreada e comida por aqui: isso foi Ciência! São esses valores de Ciência do nosso saber, saber tradicional com relação a remédio, do nosso entendimento com relação à cosmologia, do nosso entendimento com relação à religiosidade! Isso são Ciências. Mas, principalmente, do nosso entendimento com relação à Educação: como nós educamos, como queremos educar e como entendemos que é essa pedagogia da educação indígena. É essa valorização da Ciência que precisa ter uma simetria.

JDK: Imagina! Obrigada também.

Florianópolis (SC), março de 2018.

\section{REFERÊNCIAS}

NÖTZOLD, A. L.; ROSA, H. A.; BRINGMANN, S. F. (org.). Etnohistória, história indígena e educação: contribuições ao debate. Porto Alegre: Pallotti, 2012.

Endereços para correspondência: Campus Reitor João David Ferreira Lima, Centro de Educação, Sala 400, 84040-900, Trindade, Florianópolis, Brasil; elison0406@gmail.com 